\title{
Infrared Thermography Study of Heat Transfer in an Array of Round Jets
}

\author{
by J.-M. Buchlin , J. Brossard and J.-B. Gouriet
}

${ }^{*}$ von Karman Institute, Rhode Saint Genèse, Belgium

\begin{abstract}
The paper describes a study of convective heat transfer in a multiple-jet systems composed of round nozzles. The application concerned is the fast cooling of moving strip. The experimental approach involves the application of infrared thermography associated with the steady-state heated foil technique. The study aims to determine the effect on the average heat transfer coefficient of the jet Reynolds number in the range 40000 to 85000 , the normalised nozzle to strip standoff distance $Z / D$ from 2 to 10 and the normalised nozzle spacing $W / D$ from 2 to 5 . The geometrical nozzle arrangements tested include staggered and non-staggered configuration. The experimental findings are compared with an existing correlation; deviations, which are observed at small Z/D-values may reach $30 \%$.
\end{abstract}

\section{Introduction}

Impinging fluid jets are widely used in industrial processes where high momentum, heat and/or mass transfer rates have to be reached [1]. Typical applications are the jet wiping, the drying of paper and textiles, the cooling of turbine blades [2], the antiicing of aircraft $[3,4]$, the tempering of glass sheets and the cooling of moving metal strips $[4,5,6]$. This last application has been more particularly illustrated in a previous paper presented at the QIRT2002 in which experimental data of array of slot nozzles are discussed [7]. The present paper is a follow-up; emphasis is now given to systems composed of round nozzles. The aim is to determine the local and mean convective heat transfer coefficient to assess the design parameters that control thermal exchange between the gas flow and the moving strip.

The study emphasizes more specifically the effect of the jet Reynolds number, the nozzle spacing and the nozzle standoff distance on the convective heat transfer. To access to a refined description of the thermal exchange between gas jets and strip a new facility accommodating the use of infrared thermography, has been developed at the VKI.

\section{Experimental set-up}

Figure 1-a shows a schematic of the tests set-up while the photograph in figure 1-b displays a general view. a VKI-L10 wind tunnel is mimicked to accommodate the ARN system. It consists of a plenum (settling chamber) ended by a perforated square plate made in wood, $0.6 \mathrm{~m}$ side and $18 \mathrm{~mm}$ thick. The holes are circular holes of 15 $\mathrm{mm}$ in diameter,. They are drilled to form square or triangular pattern characterized by hole spacing varying between $30 \mathrm{~mm}$ and $75 \mathrm{~mm}$ as sketched in figure 2 . 
A blower delivers a flow rate between 0.1 and $0.25 \mathrm{~m}^{3} / \mathrm{s}$ under a maximum overpressure of $5000 \mathrm{~Pa}$. That's allows adjustment of the jet Reynolds number, $\mathrm{Re}=$ $\mathrm{UD} / \mathrm{v}$, from 40000 to 90000 . The jet velocity, $U$, is inferred from measurement of the plenum chamber with a pressure transducer. The jet velocity-plenum pressure correlation has been established through pitot tube measurements. Thermocouples located just at the exist of some holes allows the control of the jet temperature.

The air jets impinge on a vertical heated plate. It is a constant -uniform heat flux surface of $0.46 \mathrm{~m}$ in diameter, which consists of an electrical-circuit board made of a $40 \mu \mathrm{m}$ thick copper foil coating an epoxy sheet of $1.5 \mathrm{~mm}$ thick. The copper layer of the plates is machined to produce a double spiral continuous electrical resistance. The Joule heating is monitored by a potentiometer and measured with ammeters and voltmeters. The copper face is exposed to the impinging flow while an infrared camera scans the other side, which is painted black (emissivity 0.92). Some thermocouples are flush mounted on the heated plate to monitor the foil temperature.

The infrared radiometer is a ThermaCAM ${ }^{\circledR}$ SC3000 infrared camera equipped with GaAs-QWIP detector; it is operating on a spectral wavelength range $8-9 \mu \mathrm{m}$ and cooled by Stirling cycle. The field of view is $20^{\circ} \times 15^{\circ}$ and the minimal focus distance is $40 \mathrm{~cm}$. The thermal sensitivity of that camera at $+30^{\circ} \mathrm{C}$ is of $0.03^{\circ} \mathrm{C}$. The heated foil and the IR camera are mounted on four guide rails, which allows to vary both the standoff distance between the perforated and the heated plate from 2 to 10 nozzle diameters and the distance between the IR camera and the heated plate to modify appropriately the field of view.
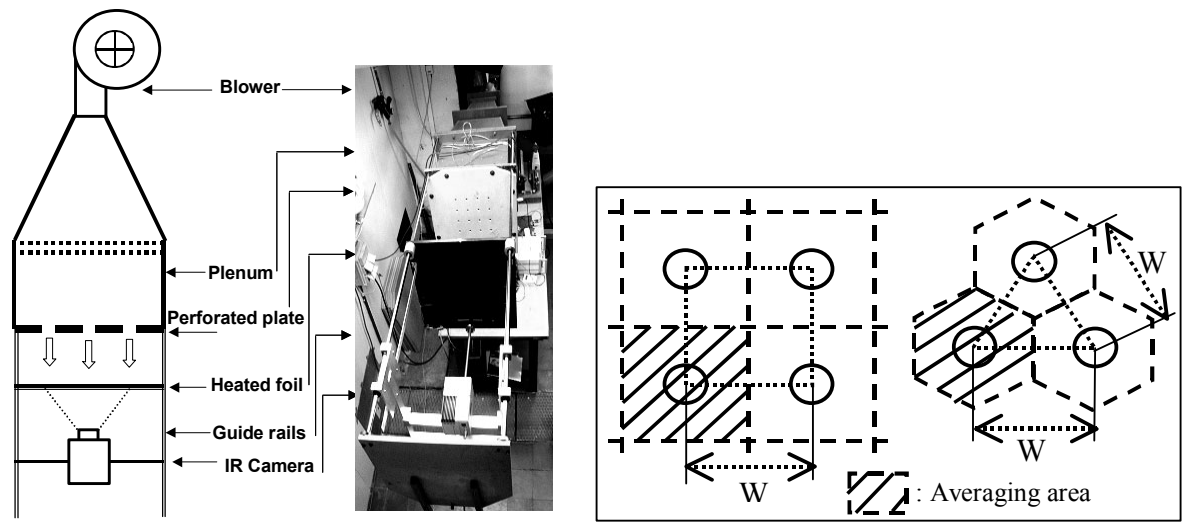

(a)

(b)

Figure 1: schematic and general Figure 2: array pattern view of the test set-up configurations tested 


\section{Data Reduction}

The measurements are conducted at steady state. To smooth out the intrinsic noise, the final thermogramme is an averaged image obtained summing 5 frames using the ThermaCAM $^{\circledR}$ Researcher2001 software [8]. The thermogrammes are exported in matrix files to be post-processed by a VKI-in-house Matlab software. The convective heat transfer coefficient is inferred from the plate surface temperature $T_{w}(x, y)$ by application of the Newton relation:

$$
h(x, y)=\frac{q_{c v}(x, y)}{T_{w}(x, y)-T_{f}}
$$

In Eq.(1) $T_{f}$ is the temperature of the jet at the nozzle exit. The convective flux $q_{c v}$ is obtained by subtracting the heat losses $q_{l}$ to the Joule heating $q_{J}$. The heat losses include the contribution of the radiation $q_{\mathrm{rad}}$, the foil conduction $q_{\mathrm{cd}}$ along the two dimensions , Ox-Oy, and the possible natural convection on the face not exposed to the flow. Making use of the two-dimensional fin theory, the following expression is applied:

$$
q_{\ell}=-e \nabla \cdot\left(k \nabla T_{w}\right)+h_{t o t}\left(T_{w}-T_{a m b}\right)
$$

$e$ and $k$ are the thickness and the thermal conductivity of the plate, respectively. The total heat transfer coefficient, $h_{\text {tot }}$, models natural convection and thermal radiation effects together. The heat transfer coefficient by radiation can be inferred from the radiosity concept [6]. Eqs. (1) and (2) show that $h_{\mathrm{cv}}$ can be determined readily once the foil properties and the temperature distribution $T_{\mathrm{w}}$ are known. Under this scheme the heat transfer coefficient can be evaluated with an uncertainty less than $10 \%$.

\section{Results}

Figure 3 displays typical mappings of the convective heat transfer coefficient for different nozzle arrangements and the minimum and maximum Reynolds number tested. Emphasis is given to the nozzle spacing. Whatever the nozzle arrangement as WD decreases the cooling the local heat transfer peak does not evolve because it mainly depends on ZD and $\mathrm{Re}$, but the plate cooling is more and more uniform. For engineering purpose like the design of industrial coolers, it is more opportune to calculate an average convective heat transfer coefficient, $<h>$ from the local distribution. 


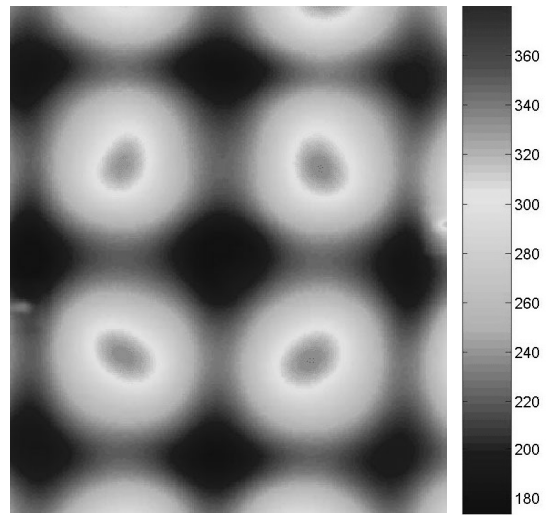

$\mathrm{WD}=5 ; \mathrm{ZD}=4$

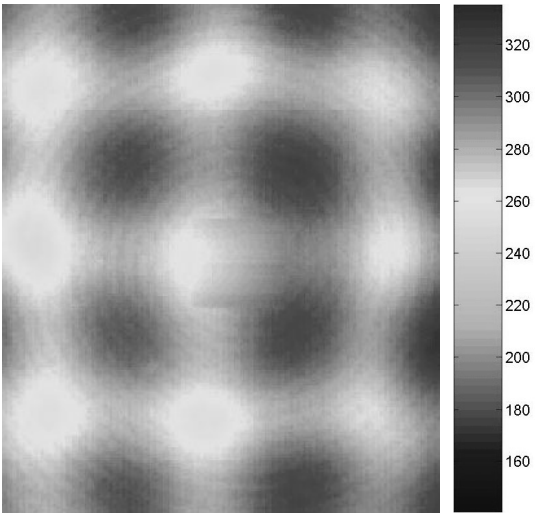

$W D=2 ; Z D=4$

Square Array $-\mathrm{Re}=85000$

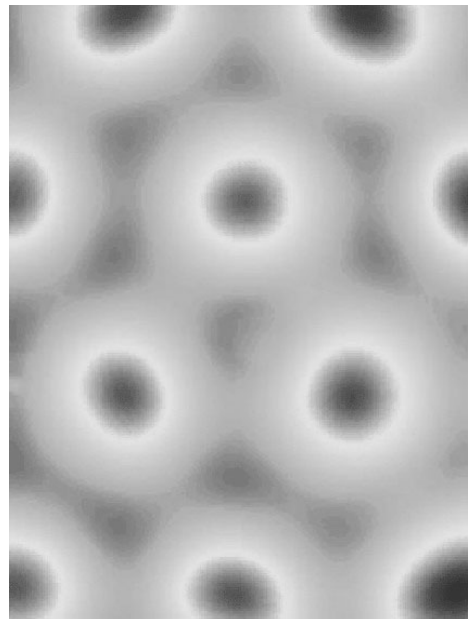

$\mathrm{WD}=5 ; \mathrm{ZD}=4$
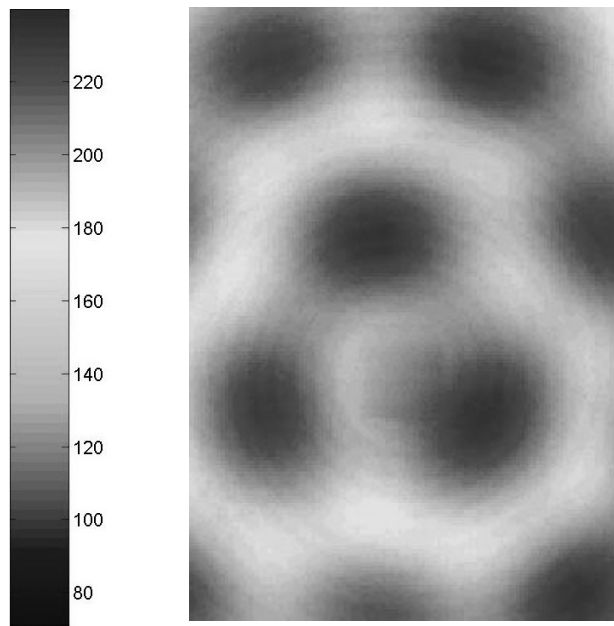

$W D=2 ; Z D=4$

Triangle Array $-\mathrm{Re}=40000$

Figure 3: Mapping of the convective heat transfer coefficient [ $\left.\mathrm{W} / \mathrm{m}^{2} . \mathrm{K}\right]$

The averaging area is equivalent to that sketched in figure 2. The mean heat transfer coefficient is expressed in terms of the average Nusselt number $\langle N u\rangle=\langle h\rangle D / k_{a}$ based on the nozzle diameter.

Figure 4 compares the evolution of $<\mathrm{Nu}\rangle$ for the two nozzle arrangements tested as the standoff distance increases. At constant Reynolds number, the average Nusselt number decreases as the normalised nozzle-to-strip distance increases. At constant 
Z/D and W/D <Nu>-value increases as the Reynolds number augments. Whatever are the flow and the geometrical parameters, no effect of the array pattern is depicted.
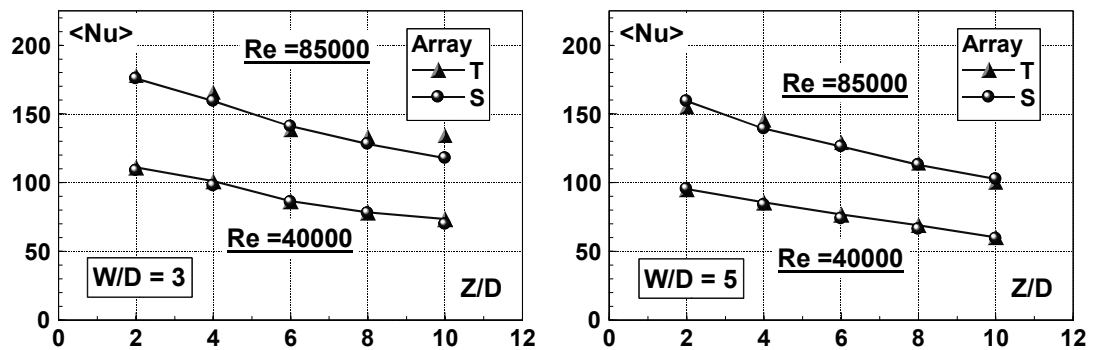

Figure 4: Mean Nusselt number versus the normalised nozzle-to-strip standoff distance

Revisiting figure 4 and plotting <Nu> versus W/D, it is shown in figure 5 that the average convective heat transfer decreases as the nozzle-to-nozzle pitch increases; this effect is less pronounced at low Reynolds number and high standoff distance.

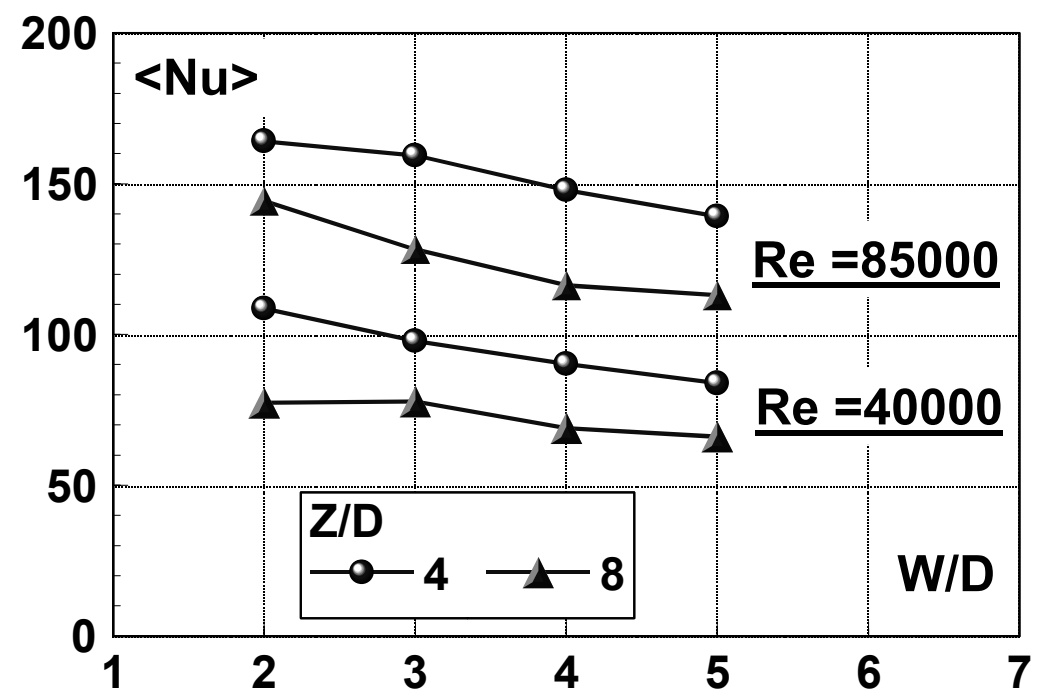

Figure 5: Mean Nusselt number versus the normalised nozzle-to-nozzle pitch

A relevant way to compare the present IR findings to published data is to reformulate the results in terms of dimensionless groups introduced by Martin [1]. The averaged Nusselt number is reduced by the fluid Prandt number, $\mathrm{Pr}$, and a geometrical function including the effect of ZD and WD as follows: 


$$
<N u^{*}>=\frac{<N u>}{\operatorname{Pr}^{0.42} G^{*} K}=\operatorname{Re}^{2 / 3}
$$

where

$$
G=\left\{\begin{array}{ccc}
1 & \text { if } & F<1 \\
F^{-0.3} & \text { if } & F>1
\end{array} \quad \text { with } \mathrm{F}=\frac{Z / D}{0.6 / \sqrt{f}} \quad \text { and } f=\frac{\frac{\pi}{4} D^{2}}{\text { Averaging Area }}\right.
$$

and

$$
K=2 \sqrt{f} \cdot \frac{1-2.2 \cdot \sqrt{f}}{1+0.2 \cdot(Z / D-6) \cdot \sqrt{f}}
$$

The correlation (3) is established from the literature data and announced to be valid for $2 \leq \mathrm{ZD} \leq 12,2000 \leq \operatorname{Re} \leq 100000$ and $0.004 \leq \mathrm{f} \leq 0.04$.

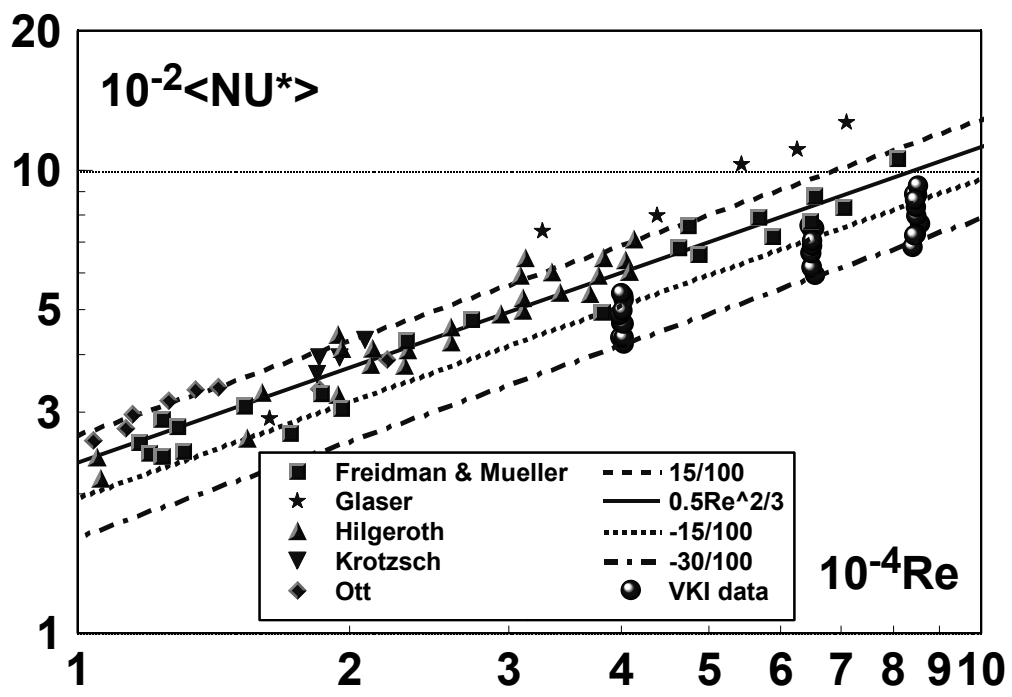

Figure 5: Reduced Nusselt number versus the jet Reynolds number

The results of the present study for the square and triangular array patterns satisfying as close as possible the conditions of application of correlation (3) are plotted in figure 5. They are compared to different published experimental data spreading in a wide range of $\mathrm{Re}$ as reported in [1]. The Martin's correlation is the continuous line .

Figure 5 shows that the IR data could be $15 \%$ to $30 \%$ lower that the prediction obtained by Eq. (3). Although the trend $\mathrm{Re} 2 / 3$ is well reproduced, the spreading of the data at constant $\mathrm{Re}$ indicates that Eq. (3) does not account satisfactorily the effect of the geometrical parameters such as ZD and WD . 


\section{Conclusions}

Local convective heat transfer coefficient in a multiple-jet systems composed of round nozzles produced by drilled holes in a plenum is experimentally determined by means of infrared thermography combined to the thermo-foil technique.

Experiments are conducted for standoff distance varying from two to ten nozzle diameters and nozzle spacing from 2 to 5 nozzle diameters. The jet Reynolds number is ranging from 40000 to 85000 .

To be directly applicable to design of strip cooling systems, the results are presented in terms of the average heat transfer coefficient. The increase of the standoff distance and/or the nozzle-to-nozzle pitch leads to a drop of the convective thermal exchange.

Arranging the round nozzles in a square or triangular pattern does not yield any difference in the final mean heat transfer coefficient.

Although the effect of the Reynolds number is well modelled by the Martin's correlations, deviations up to $30 \%$ with the present infrared data can be observed indicating that the modelling of the effect of the geometrical parameter is not satisfactory.

\section{REFERENCES}

[1] MARTIN, H. , " Heat and mass transfer between impinging gas jets and solid surfaces", Adv. Heat Transfer, Vol. 13, p. 1-60, 1977.

[2] GOLDSTEIN, H.B. , " Impingement cooling", In: Aero-Thermal Performance of Internal Cooling Systems in Turbomachines, VKI Lecture -Series 2000-03, February 28 - March 3, 2000.

[3] BUCHLIN, J-M.; PRETREL, H.; PLANQUART, P.; LANGER, H. and THIRY, F. " Infrared thermography study of a thermal anti-icing system ", In : Quantitative Infrared Thermography QIRT 94 (Balageas D, Busse G, Carlomagno GM, eds), pp. 133-138, Eds. Européennes Thermique et Industrie, 1994.

[4] BUCHLIN, J-M. and DUBOIS, M., " Heat transfer of impinging multijet system. An application of the quantitative thermography“, In : Quantitative Infrared Thermography QIRT 92 (Balageas D, Busse G, Carlomagno GM, eds), pp. 117-120, Eds. Européennes Thermique et Industrie, 1992.

[5] BUCHLIN, J-M., " Convective heat transfer in impinging-gas jet systems", In: Aero-Thermal Performance of Internal Cooling Systems in Turbomachines, VKI Lecture -Series 2000-03, February 28 - March 3, 2000.

[6] BUCHLIN, J-M.; GOURIET, J-B.; PLANQUART, P. ; VAN BEECK, J.P.A.J. and RENARD, M. , " Experimental and numerical study of convective heat transfer in an array of slot jets “, ASME Flows in Manufacturing Processes,July 14-16, 2002, Montréal, Québec , Canada

[7] BUCHLIN, J-M.; GOURIET, J-B.; PLANQUART, P. ; VAN BEECK, J.P.A.J. and RENARD, M. , " Infrared Thermography Study of Heat Transfer in an Array of Slot Jets “In : Quantitative Infrared Thermography QIRT2000 (Balageas D, Busse G, Carlomagno GM and Švaić S, eds), pp. 132-137, Eds. Zagreb, Faculty of Mechanical Engineering and Naval Architecture, 2003.

[8] FLIR SC3000 User Manual 
http://dx.doi.org/10.21611/qirt.2004.101 